\section{Conduct of the Women's Health Initiative randomised trial evaluating estrogen plus progestin: implications for breast cancer findings: authors' response}

We thank Drs Chlebowski, Nikolaenko and Anderson for their comments. ${ }^{1}$

We have previously reviewed ${ }^{2}$ the article published by Chlebowski and his colleagues in the New England Journal of Medicine, ${ }^{3}$ and the claim that it documented that "mammography use was similar in the hormone-therapy and placebo groups ... before and after the intervention [i.e. the Women's Health Initiative (WHI) clinical trial]" is incorrect. Only the percentages of breast cancer that were detected by mammography were documented.

In a subsequent article Chlebowski et al. ${ }^{4}$ stated that "mammography frequency was comparable in the two randomization groups during the original trial period ... (annualized percentage, $80 \%$ for hormone vs $80 \%$ for placebo). In the reconsenting population [i.e. women who consented for long-term follow-up after the protocol-specified trial period ended] ... the percentages of women with one or more mammograms were also comparable ... $(86 \%$ for hormone vs $86 \%$ placebo [sic])". However, the annual numbers, or the rates, of mammography among the women who stopped their treatments, either during the trial or thereafter, were not reported, and the likelihood that $\mathrm{E}+\mathrm{P}$ [estrogen plus progestogen (progestin)] users who stopped received more mammograms than placebo users who stopped was not excluded.

The statement that we "considered only three reports addressing the timing of $[\mathrm{E}+\mathrm{P}]$ use and breast cancer incidence" is again incorrect ${ }^{5}$ : we considered 31 reports (References 11-16, $23,29,31,32,34,36-41,43-56$ in our previous article). ${ }^{5}$ And while we regret having overlooked seven recently published reports, ${ }^{6-12}$ they do not explain the inconsistent findings reported from the same databases, or from the same countries. ${ }^{5}$ Nor do they necessitate any change in our conclusion that "a decline in breast cancer incidence should consistently have been observed in all or virtually all ... studies, and it has not been". Nor do they change our further conclusion that "the decline should also have continued for several years, and it did not".

Chlebowski et al. are once again incorrect when they quote us as having stated that participants were "dropped from follow-up when they discontinued study medication". ${ }^{2}$ We made no such statement.

Chlebowski et al. argue that "empirical ... evidence from the WHI trial undercuts [our] argument that unblinding ... due to bleeding may have caused detection bias" since in that case "one would have expected an increased risk during the first 2 years", but a decreased risk was instead observed. That decrease could have been due to chance: in Years 1 and 2 of follow-up ${ }^{13}$ the hazard ratios were 0.62 (based respectively on 11 and $17 \mathrm{E}+\mathrm{P}-$ and placebo-exposed cases) and 0.83 (26 and 30 cases); 95\% confidence intervals were not given. In addition, $\mathrm{E}$ $+\mathrm{P}$ users subjected to the need to rule out endometrial cancer would also have become concerned about the possibility of breast cancer, especially since they were already informed at baseline that this was an outcome under study. With the passage of time they would progressively have become more concerned. The respective 'unblinding' rates were $44.4 \%$ and $6.8 \%$ in the $\mathrm{E}+\mathrm{P}$ and placebo recipients, ${ }^{13}$ and detection bias was inevitable.

With regard to confounding, consider a hypothetical clinical trial in which $100 \%$ of the participants soon become non-adherent to their assigned treatments, after which follow-up continues for years. As is obvious, an 'intention-to-treat' analysis would be absurd. In the WHI trial ${ }^{13}$ the respective discontinuation rates of $42 \%$ and $38 \%$ in the $\mathrm{E}+\mathrm{P}$ and placebo recipients came more than one-third of the way to conforming with that absurdity. To minimise both detection bias and confounding the WHI investigators have repeatedly been challenged to publish an 'as treated' analysis confined to women who remained both 'blinded' and adherent. ${ }^{2}{ }^{14}$ Thus far they have failed to do so.

Chlebowski et al. express the opinion that it is incorrect to "apply a linear response criteria [sic] on an intervention that not only increased the endpoint (breast cancer) but decreased the chance of identifying that endpoint (by interfering with breast cancer detection)". If what is meant by that opinion is that increased breast tissue density among $\mathrm{E}+\mathrm{P}$ users could have interfered with the detection of breast cancer, the increased density would also have augmented the likelihood of detection bias. $^{2}$ The plain fact is that a monotonic duration-response effect was not identified.

With regard to biological plausibility, Chlebowski et al. split hairs when they argue that the concepts of initiation and promotion are outmoded, and that he and his colleagues instead "suggested that $[\mathrm{E}+\mathrm{P}]$ stimulates growth of already established breast cancers". Exactly when a genetically damaged cell becomes an established breast cancer cell is unclear, but the hypothesis was that $\mathrm{E}+\mathrm{P}$ accelerates the multiplication of such cells, and hence the onset of clinically detectible breast cancer. And there is no experimental evidence to support the speculation that the withdrawal of $\mathrm{E}+\mathrm{P}$ may have effects similar to those of tamoxifen, aromatase inhibitors or oophorectomy.

Samuel Shapiro, MB, FRCP(E)

Visiting Professor of Epidemiology, Department of Epidemiology, University of Cape Town, Cape Town, South Africa; samshap@mweb.co.za

\section{Richard D T Farmer, MB, PhD}

Emeritus Professor of Epidemiology, Department of Epidemiology, University of Surrey, Guildford, UK; richard.farmer1@btopenworld.com

\section{John C Stevenson, FRCB. MFSEM}

Consultant Physician and Reader in Metabolic Medicine, National Heart and Lung Institute, Imperial College London, Royal Brompton Hospital, London, UK; j.stevenson@imperial.ac.uk

\section{Henry G Burger, MD, FRACP}

Emeritus Director, Prince Henry's Institute of Medical Research, Monash Medical Centre, Clayton, Victoria, 
Australia; Consultant Endocrinologist, Jean Hailes Medical Centre for Women's Health, Clayton, Victoria, Australia; henry.burger@princehenrys.org

Alfred 0 Mueck, MD, PhD

Professor of Clinical Pharmacology and Endocrinology, Department of Endocrinology, University Women's Hospital, Tubingen, Germany; anne.gompel@cch.aphp.fr

\section{Anne Gompel}

Professor of Gynaecology, Gynaecological Endocrinology Unit, Paris Descartes University, APHP, Port-Royal Hospital, Paris, France; anne.gompel@htd.aphp.fr

Competing interests Samuel Shapiro, John Stevenson, Henry Burger, Alfred Mueck and Anne Gompel presently consult, and in the past have consulted, with manufacturers of products discussed in this article. Richard Farmer has consulted with manufacturers in the past.

Provenance and peer review

Commissioned; internally peer reviewed.

J Fam Plann Reprod Health Care 2013;39:228-229. doi:10.1136/fprhc-2013-100673

\section{REFERENCES}

1 Chlebowski RT, Nikolaenko L, Anderson G. Conduct of the Women's Health Initiative randomised trial evaluating estrogen plus progestin: implications for breast cancer findings. J Fam Plann Reprod Health Care 2013;39:226-228.

2 Shapiro S, Farmer RDT, Mueck AO, et al. Does hormone replacement therapy cause breast cancer? An application of causal principles to three studies. Part 2. The Women's Health Initiative: estrogen plus progestogen. J Fam Plann Reprod Health Care 2011;37:165-172.

3 Chlebowski RT, Kuller L, Prentice RL, et al. Breast cancer after estrogen plus progestin use in postmenopausal women. $\mathrm{N} \mathrm{Engl} \mathrm{J} \mathrm{Med}$ 2009;360:573-587.

4 Chlebowski RT, Anderson GT, Gasss M, et al. Estrogen plus progestin and breast cancer incidence and mortality in postmenopausal women. JAMA 2010;304:1684-1692.

5 Shapiro S, Farmer RDT, Stevenson JC, et al. Does hormone replacement therapy (HRT) cause breast cancer? An application of causal principles to three studies. Part 5. Trends in breast cancer incidence in relation to the use of HRT. J Fam Plann Reprod Health Care 2013;39:80-88.

6 Farhat GN, Walker R, Buist DS, et al. Changes in invasive breast cancer and ductal carcinoma in situ rates in relation to the decline in hormone therapy use. J Clin Oncol 2010;28:5140-5146.

7 Renard F, Vankrunkelsven P, van Eycken L, et al. Decline in breast cancer incidence in the Flemish region of Belgium after a decline in hormone replacement therapy. Ann Oncol 2010;21:2356-2360.
8 Pritwish DC, Neutel CI, Morrison H. Breast cancer incidence and hormone therapy in Canada. J Natl Cancer Inst 2010;102:1489-1495.

9 Von Euler-Chelpin M. Breast cancer incidence and use of hormone therapy in Denmark 1978-2007. Cancer Causes Control 2011;22:181-187.

10 Rusner C, Bandemer-Greulich IJ, Stegmaier C, et al. Population-based hormone receptorspecific incidence trends of breast cancer in Germany. Maturitas 2012;73:152-157.

11 Hofvind S, Sakshaug S, Ursin G, et al. Breast cancer incidence trends in Norway explained by hormone therapy or screening? Int J Cancer 2012;130:2930-2938.

12 Zbuk K, Anand SS. Declining incidence of breast cancer after decreased use of hormone-replacement therapy: magnitude and time lags in different countries. J Epidemiol Community Health 2012;66:1-7.

13 Writing Group for the Women's Health Initiative Investigators. Risks and benefits of estrogen plus progestin in healthy postmenopausal women. Principal results from the Women's Health Initiative randomized controlled trial. JAMA 2002;288:321-333.

14 Shapiro S. Risks of estrogen plus progestin therapy. A sensitivity analysis of findings in the Women's Health Initiative randomized controlled trial. Climacteric 2003;6:302-310. 